\title{
The Effect of the Changing Diversity Climate After Covid-19 on Employees' Behaviour in Omani Companies
}

Syed Sadullah Hussainy

Faculty of Business, Arab Open University, Sultanate of Oman

\begin{tabular}{l} 
ARTICLE INFO \\
\hline Keywords: \\
Diversity Climate \\
Covid 19 \\
Citizen and Expatriate \\
Employees
\end{tabular}

\section{Introduction}

Diversity climate, also known as psychological climate. It refers to employees' perceptions of the organization's diversity policies, and practices. To put it another way, the Diversity Climate is described as an organizational climate characterized by acceptance, tolerance, equity, and inclusion of diversified sets of employees in organization (McKay, Patrick \& Avery, Derek. 2015). Organizations must have solid strategies in place to handle a diverse workforce and create a supportive Diversity Climate in order to gain a competitive advantage (Bassett-Jones, N. 2005) The movement of individuals, companies, and industries across the countries of the globe has increased due to globalization and internationalization. Over the last few decades, global migration has risen, and developing and wealthy countries now host more than half of all foreign migrants (Jacob Poushter \& Janell Fetterolf, 2019). Middle

\footnotetext{
* Corresponding author E-mail address: syed@aou.edu.om

Cite this article as:

Hussainy, S. S. (2021). The Effect of the Changing Diversity Climate After Covid-19 on Employees' Behaviour in Omani Companies.
} International Journal of Applied Research in Management and Economics, 4(2), 1-12. https://doi.org/10.33422/ijarme.v4i2.628

(C) The Author(s). 2021 Open Access. This article is distributed under the terms of the Creative Commons Attribution 4.0 International License, which permits unrestricted use, distribution, and redistribution in any medium, provided that the original author(s) and source are credited. 
eastern countries have become centre for migration because of their modest culture, simple lifestyle, equality, high tolerance for others, decent living standards, a range of business and work opportunities, and a friendly environment to live. As stated by Pew Research Centre, USA (2018) In the last few decades, GCC countries have attracted people from all over the world. The migrants and expatriates outnumbering citizens in some of the GCC countries such as Kuwait, Bahrain, and UAE. Organizations operating in the GCC regions have been hiring and engaging workers from all over the world for the past four decades and Oman is one among them. As reported in the "Times of Oman" (Oct. 2019) Oman has a total population of 4.5 million people, with 2.7 million Omanis and 1.75 million expatriates. The national newspaper "Oman Observer" (Oct,2019) gave the news that, Oman is home to workers from all over the world, making it the second most diverse workforce in middle eastern region.

According to World Bank (Oct 2020) the Covid-19 affected economy of countries in the middle eastern region and on Sultanate of Oman its impact is severe. It has reduced consumer spending, products' demand, and affected the tourism and travel. Government-imposed controls on movement and transport have resulted in lower industry sales and forced companies to lay off workers. The government is under increasing pressure to create jobs for its people due to rising unemployment among fresh graduates and the young Omani population, as well as instability in industries, and the economy. The government of Oman has been speeding up the Omanization of jobs and taking various steps to provide jobs to Omani job seekers to generate more job opportunities for the citizens to control the country's rising unemployment rate. Oman's Ministry of Labour has implemented ambitious policies and aims to provide hire its citizens in both the public and private sectors. Companies began firing expatriate workers as part of the Omanization initiative, resulting in the loss of thousands of expatriate jobs in 2020. Many private-sector jobs, such as those in insurance firms, car dealerships, finance, banks, and money exchange houses, will be nationalized, and besides that, all administrative positions will be restricted to Omanis, as instructions given by the ministry of labour. Besides that, the government of Oman has raised fees for expatriate visas and placed stringent rules and restrictions on the recruitment of expatriate workers, making recruitment of expatriate workers more difficult, complex, and costly. The government has stopped renewing the work permit for all the before stated professions after their expiry date and instructed HR officials of those companies to begin training and skill transfer to Omani citizens. According to statistics published in the national newspaper, "The Oman Observer, April- 2020" the overall expatriate workforce has decreased by $15 \%$, with a $20 \%$ drop in the government sector following the pandemic, which has wreaked havoc on the 1.75 million existing expatriate workforces across industries. Expatriate employees around the board are feeling nervous, and their morale and commitment are diminishing as a result of the uncertainties that have arisen as a result of the changing diversity climates in their organizations. From this scenario, we can understand that engaging a multi-national workforce is one of the greatest challenges for the organizations in Oman. Mr. Hussain, an HR specialist for one of Oman's largest firms, continues to believe that expatriate skills are critical to the organization's success. He went on to say that businesses should continue to employ professional expatriates until the Omani workforce is completely capable of handling business affairs. A company with the right organizational climate, which includes acceptance, tolerance, fairness, and inclusion, would be able to get the most out of their workers, which is crucial for their success.

\section{Literature Review}

Currently, businesses operate in many markets, necessitating the hiring of workers of various nationalities, cultures, and religious beliefs (Cooke, F. L., \& Saini, D. S. ,2010). Companies today take pride in having a diverse workforce because it fosters innovation and creativity 
within the company and makes it more attractive to a broader variety of consumers outside (Choi, S., \& Rainey, H. G.,2010). Employees will enjoy working in a more diverse community because they will be able to collaborate and learn from one another (Nnadi, C. S. O., \& Chinedu, U. A., 2019). Many researchers accept that the good diversity climate in the organization benefits outweigh the disadvantages of managing diverse sets of employees. Diversity in organization will help the organization in getting varying perspectives on how to recognize and meet the needs of various customers (Preeti Bedi, Poonam lakra, Ekanshi Gupta, 2014). Covid-19 has elevated the value of having effective diversity practice to achieve creativity and innovation in the enterprise. It is due to reason that companies of all sizes are searching for ways to minimize costs while still improving productivity and effectiveness, which can be accomplished by a managing diverse workforce.

Previous researchers Khan, Faisal \& Sohail, Amir \& Sufyan, Muhammad \& Uddin, Maaz \& Basit, Abdul (2019), have acknowledge that, positive diversity climate will improve a company's skills and competencies, resulting in increased efficiency, gaining competitive edge in the market and provide more opportunities for businesses to succeed. To reap the benefit from the diversity it is essential to have positive Diversity Climate and for developing positive Diversity Climate, good diversity practices must be in place. As stated by (Weiliang, E. C., 2011), diversity may not be understood, or its advantages embraced if it is not handled properly. Employees of various nationalities, religions, and socioeconomic backgrounds often mask their identities, making it difficult to know how they feel and what they want, making them vulnerable in the organizations. It is management's duty to handle the diverse group of workers in the best possible way in order to get the most out of them. Developing positive Diversity Climate and promoting diversity in all activities of organization such as recruitment, allotment of work, promotion, and reward etc is essential. Employees will not choose to stay with a company if they are not treated equally and respectfully, or if the influence of stereotyping outweighs their individual value (Stazyk, E. C., Davis, R., \& Liang, J. 2012). Having healthy diversity climate can provide and/or serve as an intrinsic opportunity to boost employees' productivity, motivate them to work, and encourage dedication, a positive attitude toward work, and job satisfaction (De cieri, Costa, Pettit, \& Buttigieg, 2008).

\subsection{A Conceptual Framework}

The Covid-19 pandemic and the Sultanate's job nationalization program have affected and brough changes to normal practices across industries. Previous researchers have made theoretical and empirical contribution on various aspect of Diversity Climate in different industrial and organizational setup, but no focus has been given to the topic of Diversity Climate especially in Oman context after the Covid-19. For exploring the state of Diversity Climate in the organizations of Oman after Covid-19, the researcher has taken up this study and believe that the findings of this research will enable managers of the organization to understand impact of changing Diversity Climate on the Behaviour of employees in the organizations of Oman. The researcher likes to look at the Diversity Climate using two variables i.e., Organizational Factor, and Relational Factors, and want to understand how these two factors affect employee behaviour. Organizational and relational factors are taken as independent variables, whereas employees' behaviour, which is the product of organizational and relational factors, are considered dependent variables. 


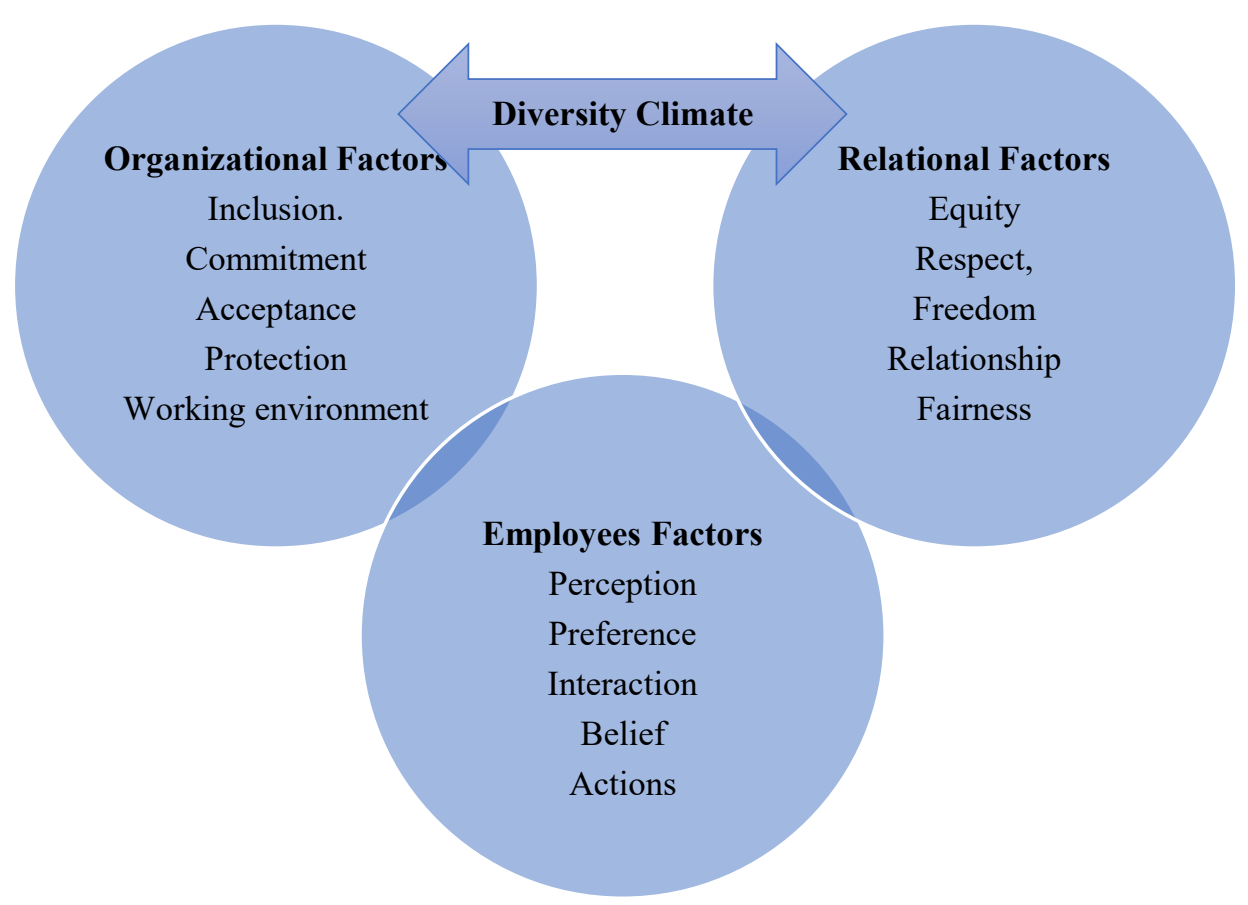

Figure 1. A Conceptual Framework

Source. Design and developed by the researcher

\subsubsection{Organizational Factor}

According to Newman, Alexander \& Nielsen, Ingrid \& Smyth, Russell \& Hirst, Giles. (2018) organizational factors are those factors which influence diversity climate of the organizations and effects employees' behaviour. They include, inclusion polices, commitment, acceptance and involvement, employment/ job security and working environment. The emphasis of inclusion policies should be on how well diverse employees are integrated into the organizational structure (Hofhuis, J., van der Rijt, P.G.A. \& Vlug, M, 2016). The dedication and commitment of top management to improve Diversity Climate by adopting appropriate practices in the organization is also critical. All managers, particularly top management, must recognize and support organization-wide strategy (Bunderson, J. S., \& Sutcliffe, K. M.,2002). Top management is in charge of the organization's teams and individual staff. If they are not on board with a new initiative or strategy, the company will suffer, and the strategy may not get very far. Acceptance and involvement of diverse set of workers in various roles, responsibilities of the company are important, because without acceptance diversity can lead to a toxic culture and climate (Choi, S. 2008). Organizations will not reap benefit of diversity only with having diversity in their workforce unless all are given equal freedom and opportunity to speak and take different roles and positions in the organizations. Employment security is important for all (citizens and expatriates). Employee terminations based on nationality status would have a greater impact on the morale, motivation, and satisfaction of those who remain with the company. Organizations are largely influenced by the uncontrollable environmental force such as changing government's employment policies and pandemic affect confusing manager and creating difficulty to have good diversity practices. Last providing conducive working environment is vital to manage the diverse workforce. Having flexibility and conducive working environment in diversified workplace means the organizations must be able to adapt to the needs to diverse workers and making them happy, satisfied, and comfortable at work (Groeneveld, S.,2011). 


\subsubsection{Individual Factors}

Individual factors are those that contribute to the creation of a positive and healthy psychological climate among employees and helping them to perform better and contribute more to their organizations. These relational factors are equity, respect, freedom, and fairness. Equity refers to a workplace atmosphere in which all workers, regardless of race, culture, or nationality, have an equal opportunity to engage in and participate in organizational activities (Cooke, F. L., \& Saini, D. S. 2010). Respect relates to appropriately valuing and honouring employees' efforts and contributions, ensuring that employees have a safe working atmosphere free of all forms of discrimination. Allowing workers to share their feelings and views openly and freely would strengthen the organization's diversity environment. Managers who efficiently exercise fairness to their workers are transparent, consistent, and equitable (Groeneveld, S., \& Verbeek, S. 2012). When a manager practices interactional justice, for example, he or she may hire an employee based on their expertise, merit, and success. Aside from that, organizations should be fair which is critical for effective employee inclusion and participation in companies, and without it, involvement and inclusion cultures would fail (Hostager, T. J., \& De Meuse, K. P. 2008) Discrimination and racism must not exist in the workplace when working with workers of all types and backgrounds (Hostager, T. J., \& De Meuse, K. P.,2002)

\subsubsection{Behavioural Factors}

Organizational and Relational factors influence employees' behaviour. Organizations who practice Inclusion, Commitment of leadership, Acceptance culture, employment Security and flexibility etc., will be creating positive influence on behaviour and attitude of employees toward diversity practices. On the other side organizations should encourage fairness, equality, independence, and justice etc., for all, which will foster a positive diversity climate and develop positive perception and attitude among employees about the diversity practices (Mor Barak, M. E.,2015). Employees will value diversity and will perceive diversity is important in organization. Similarly, the behaviour can be seen in the action and interaction inside the organization. Employees we are satisfied and feel valued in the organization certainly will be developing positive feeling and psychological contract. Such employees will put all their best for the organizations.

\subsection{Objectives}

The objectives of the studies as follows,

1. To investigate the employees' perception on Diversity Climate of the organizations.

2. To compare the perception of citizens and expatriate employees on Diversity Climate.

3. To find the changes in diversity practices of organizations in Oman after Covid- 19.

\subsection{Hypotheses}

Hypotheses are predictive proposition about the possible outcome of the research. They refer to a simple inference or supposition that must be proven or contradicted. The following hypotheses have been tested to achieve the desired result.

- H0: There is no changes in Diversity Climate of the organizations in Oman after Covid-19.

- H01: The organizational factors do not affect the employees' behaviour.

- H02: The relational factors do not affect the employees' behaviour.

- H03: There is no difference in perception between Omani and Expatriate employees with regard to diversity climate in the organizations of Oman.

- H04: There is no difference in perception between Omani and expatriate employees with regard to changes in diversity practices after covid. 


\section{Analysis of Data \& Findings}

\subsection{The Analysis of Demographic Profile of the Respondents:}

The data collected using primary instruments questionnaires is given interpretation by analysis of the study data. The study's collected primary data was analysed with the aim of obtaining useful information through the use of a few statistical methods such as Mean, standard deviation, variance, and correlation co-efficient etc. The data was gathered from employees working in Oman-based organizations in a variety of positions, with the aim of better understanding the Diversity Climate from the employees' perspective. The research was carried out in the Muscat and the data was collected from Omani and expatriate employees working in the private and public sectors. The questionnaire was sent to more than 300 people by using online survey forms (google forms), but only 117 people responded, giving it a 90 percent confidence level and an 8 percent margin of error, which is acceptable if the sample size is small as stated by ISixSigma in their official website. Due to the Covid pandemic, the researcher was unable to follow up with the respondents to obtain additional answers. According to the demographic profile of the study, 77 (66\%) of the 117 people who answered to the survey were male and $40(34 \%)$ were female. Omani citizens accounted for $79(67.5 \%)$ of the respondents, while expatriate workers accounted for $38(32.5 \%)$.

\subsection{Descriptive \& Mean Analysis}

Table 1.

Overall Employees' Perception on Diversity Climate

\begin{tabular}{|c|c|c|c|c|c|}
\hline S. No & Variable & $\mathbf{N}$ & Mean & SD & Variance \\
\hline \multicolumn{6}{|c|}{ Organizational Factors } \\
\hline 1 & Inclusion Policy & 117 & 3.90 & 1.05 & 1.11 \\
\hline 2 & Management Commitment & 117 & 2.76 & 1.04 & 1.09 \\
\hline 3 & Acceptance & 117 & 3.20 & 1.23 & 1.51 \\
\hline 4 & Employment Security & 117 & 3.35 & 1.21 & 1.48 \\
\hline \multirow[t]{2}{*}{5} & Working environment & 117 & 3.41 & 1.11 & 1.23 \\
\hline & Total & & 16.62 & 5.64 & 6.42 \\
\hline \multicolumn{6}{|c|}{ Relational Factor } \\
\hline 1 & Equity & 117 & 3.15 & 1.20 & 1.46 \\
\hline 2 & Respect & 117 & 3.77 & 1.04 & 1.09 \\
\hline 3 & Freedom & 117 & 3.42 & 1.22 & 1.49 \\
\hline 4 & Relationship with superiors and co-workers & 117 & 3.27 & 1.23 & 1.51 \\
\hline \multirow[t]{3}{*}{5} & Transparency & 117 & 3.15 & 1.20 & 1.46 \\
\hline & Total & & 16.76 & 5.89 & 7.01 \\
\hline & Grand Total & & 33.38 & 11.53 & 13.43 \\
\hline \multicolumn{6}{|c|}{ Employee/ Individual Behavior } \\
\hline 1 & Perception/ View about Diversity & 117 & 3.99 & 0.82 & 0.67 \\
\hline 2 & $\begin{array}{l}\text { Preference/ Willingness to work in diversified culture } \\
\text { and environment. }\end{array}$ & 117 & 3.98 & 1.01 & 1.02 \\
\hline 3 & Interaction & 117 & 3.79 & 0.88 & 0.77 \\
\hline 4 & Belief/ faith that diversity climate will improve & 117 & 3.27 & 1.23 & 1.51 \\
\hline \multirow[t]{2}{*}{5} & Action & 117 & 3.41 & 1.11 & 1.23 \\
\hline & Total & & 15.17 & 3.81 & 3.69 \\
\hline Chang & in Diversity Climate After Covid & 117 & 3.56 & 1.02 & 1.04 \\
\hline
\end{tabular}

Employee perceptions of the Diversity Climate in an Oman-based companies were assessed using descriptive-mean analysis. Overall, employees' perception of Diversity Climate is significantly above average, as per the findings. Independ sample " $t$ " test have been used to test the hypothesis. Since in the result $\mathrm{P}$ value of the independent sample " $\mathrm{t}$ " test is greater than the Sig. Value (0.05) and the diversity climate score is $(0.45)$, the Hypothesis (H0) is rejected as the outcome is not relevant. It is understood that Diversity Climate is changed and affected due to Covid 19 in the organizations of Oma. In mean analysis the 
Employee perception of the "Inclusion Policy" is the highest among the organizational factors of diversity climate, with a mean score of 3.90, and the lowest in the case of management engagement, with a mean score of 2.76 , indicating that presently companies have workers from different nationality but after the Covid-19, companies' management are not committed to having diversity workforce. This could be attributed to changes in government regulations and increased government fees of the expatriate recruitment. Employee perception of relational variables is highest on the variable respect, which is having mean score of 3.77, and openness and transparency in the activities are the lowest which are having mean score of 3.15. When it comes to employee behavior, the results show that employees' perceptions and view about the diversity and the atmosphere of Diversity, receive the highest scores, accompanied by their preference and willingness to work in a diversified environment. Employees' expectation that diversity climate will change in the future has a weaker mean score, indicating that a significant portion of employees believe that diversity climate will not improve after the Covid-19 because of the government job nationalization program.

To understand the effect of organizational and relational factors on employee behavior, the researcher measured the relationship between organizational and relational factors with employees/individual behavior. To determine the " $\mathrm{R}$ " value and $\mathrm{P}$-values, the correlation co-efficient was used. The $\mathrm{R}$ value is -0.702 , and the $\mathrm{p}$-value (Sig. Value) is 0.45 , greater than the Sig. Value (0.05). It is suggesting that organizational factors of have little impact on employees' behavior. When evaluating the impact of relational factors on employee behavior, the findings indicate that they have a positive impact and correlation. The " $R$ " value was 0.4622 , while the P-value (Sig value) was 0.0001 . As a result, H01 is accepted while $\mathrm{H} 02$ is rejected.

\subsection{Employees' Perception on Diversity Climate}

Table 2.

Comparison Between Omani \& Expatriate Employees: Mean Analysis

\begin{tabular}{|c|c|c|c|c|c|c|c|c|c|}
\hline No & Variable & O- $\mathbf{N}$ & M & SD & V & E-N & $\mathbf{M}$ & SD & $\mathbf{V}$ \\
\hline & Organizational Factors & & & & & & & & \\
\hline 1 & Inclusion Policy & 79 & 3.79 & 0.93 & 0.87 & 38 & 4.13 & 1.23 & 1.55 \\
\hline 2 & Management Commitment & 79 & 2.73 & 1.05 & 1.12 & 38 & 3.57 & 1.01 & 1.03 \\
\hline 3 & Acceptance & 79 & 3.18 & 1.26 & 1.59 & 38 & 3.23 & 1.15 & 1.33 \\
\hline 4 & Employment Security & 79 & 3.77 & 1.11 & 1.23 & 38 & 2.47 & 0.85 & 0.92 \\
\hline \multirow[t]{3}{*}{5} & Working environment & 79 & 3.79 & 0.93 & 0.87 & 38 & 3.18 & 1.04 & 1.09 \\
\hline & Total & & 17.26 & 5.28 & 5.68 & & 16.58 & 5.28 & 5.92 \\
\hline & Relational Factor & & & & & & & & \\
\hline 1 & Equity & 79 & 3.26 & 1.26 & 1.61 & 38 & 2.92 & 1.03 & 1.07 \\
\hline 2 & Respect & 79 & 3.81 & 1.04 & 1.09 & 38 & 3.71 & 1.04 & 1.10 \\
\hline 3 & Freedom & 79 & 3.45 & 1.27 & 1.61 & 38 & 3.36 & 1.11 & 1.23 \\
\hline 4 & Relationship with superiors and co-workers & 79 & 3.27 & 1.33 & 1.77 & 38 & 3.26 & 0.99 & 0.98 \\
\hline \multirow[t]{4}{*}{5} & Transparency & 79 & 3.51 & 1.12 & 1.26 & 38 & 2.92 & 1.03 & 1.07 \\
\hline & Total & & $\mathbf{1 7 . 3}$ & 6.02 & 7.34 & & 16.17 & 5.20 & 5.45 \\
\hline & Grand Total & & 34.56 & 11.3 & 13.02 & & 32.75 & 10.48 & 11.37 \\
\hline & Employee/ Individual Behavior & & & & & & & & \\
\hline \multirow{2}{*}{$\begin{array}{l}1 \\
2\end{array}$} & Perception/View about Diversity & 79 & 3.91 & 0.90 & 0.81 & 38 & 4.15 & 0.58 & 0.53 \\
\hline & $\begin{array}{l}\text { Preference/ Willingness to work in diversified } \\
\text { culture and environment. }\end{array}$ & 79 & 3.82 & 1.12 & 1.25 & 38 & 4.31 & 0.61 & 0.37 \\
\hline 3 & Interaction & 79 & 3.73 & 0.95 & 0.90 & 38 & 3.92 & 0.70 & 0.49 \\
\hline 4 & Belief/ faith that diversity climate will improve & 79 & 3.63 & 1.04 & 1.09 & 38 & 3.71 & 1.04 & 1.10 \\
\hline \multirow[t]{3}{*}{5} & Actions & 79 & 3.45 & 1.27 & 1.61 & 38 & 4.13 & 1.23 & 1.55 \\
\hline & Total & & 18.54 & 5.28 & 5.66 & & 20.22 & 4.16 & 4.04 \\
\hline & $\begin{array}{l}\text { Changes in Diversity Climate After } \\
\text { Covid }\end{array}$ & 79 & 3.63 & 1.04 & 1.09 & 38 & 3.18 & 1.04 & 1.09 \\
\hline
\end{tabular}


The relationship between organizational and relational factors and the behavior of citizen (Omani) and expatriate employees was investigated by the researcher. The correlation coefficient was used to determine the relationship between organizational factors and Omani employees' behavior. The P Value is greater than the Sig. Value (0.05) in the case of organizational factors and employee behavior (0.67). Organizational factors and employee behavior have been found to have little positive co-relations $(r=0.038)$. The researcher further evaluated the relationship between relational factors and Omani employee behavior. The P value is greater than the Sig. Value $(0.05)$ in the case of the relationship between relational factor and employee behavior (0.97). No co-relations between relational factor and employee behavior have been found $(r=0.00)$. This study also measured the relationship between organizational and relational factor for expatriate employees. The P Value is less than the Sig. Value (0.05) in the case of expatriate employees' impressions of organizational variables and employee behavior $(0.00)$. The correlation co-efficient has also been used to determine the relationship between relational factors and expatriate employee behavior. The $\mathrm{P}$ value is greater than the Sig. Value (0.05) in the case of expatriate employees' perception on relational factor and behavior of employees (0.41). So, the $\mathrm{H} 03$ is rejected because there is a difference between in the overall perception of Omani (Citizen) employees and expatriate employees' perception with regard to Diversity Climate.

Table 3.

Omani Employees (Gender Based) Perception on Changes in Diversity Practices After Covid 19

\begin{tabular}{cccccc}
\hline S. No & N & Mean & Median & Standard Deviation & Variance \\
\hline Female & 32 & 3.50 & 4 & 1.25 & 1.56 \\
Male & 47 & 3.53 & 4 & 1.02 & 1.05 \\
\hline
\end{tabular}

Table 4.

Expatriate Employees (Gender Based) Perception on Changes in Diversity Practice After Covid-19

\begin{tabular}{cccccc}
\hline S. No & N & Mean & Median & Standard Deviation & Variance \\
\hline Female & 08 & 3.37 & 3 & 0.99 & 0.98 \\
Male & 30 & 3.13 & 3 & 1.05 & 1.11 \\
\hline
\end{tabular}

The above table shows that both Omani and expatriate employees of both genders agree that the Diversity practices of their organizations has changed as a result of Covid-19, and that their perception is above average. The "t test" of two independent means was used to evaluate the difference in perception between expatriate and Omani employees regarding the effect of Covid-19 on diversity practice. The t value is 2.19 , and the P-value is 0.79 , which is higher than the Sig. P-value of 0.05 . As a result, H04 is accepted.

\subsection{Limitation of the Study}

The first weakness of this study is the sample size, which is very small due to covid-19, the researcher was only able to collect data from 117 respondents while putting in a lot of effort. Secondly, identifying diversity climate factors and linking them to employee behavior is also difficult due to the ambiguity of objective measurement. Organizational factors discussed in this study, such as inclusion, commitment, acceptance, protection, and culture, vary from one organization to another, as does the impact these factors have on employees' behavior and performance. Furthermore, the Diversity Climate model suggested in this study is theoretical, and it must be evaluated and tested for efficacy, should be modified as needed by the organization. This model will assist and serve as a reference, but it is not meant to be static, as each company's needs and priorities for developing a positive Diversity Climate are unique. 


\section{Conclusion \& Discussion}

In today's global marketplace, having a positive Diversity Climate is critical to maintain and increase competitive advantage (Beechler, S., \& Woodward, I. C. 2009). Top management should take the changing diversity climate seriously and develop appropriate strategies to get a positive impact of changing Diversity Climate for organizational benefit (McKay, P. F., Avery, D. R., Tonidandel, S., Morris, M. A., Hernandez, M., \& Hebl, M. R.,2007). To achieve long-term organizational sustainability, careful planning is important to make the most of Omani workers' skill. Good workforce management will help in recruiting the best Omani employees and retain both Omani and expatriate employees at present and also in future. It is well recognized that political and government issues have a significant impact on management commitment, but companies should use appropriate strategies to retain expatriate employees and get the most out of them in order to enhance and increase organizational efficiency. Aside from that, they should continue to train Omanis to improve their skills and competencies so that they can take on important roles within the organization. With Oman's government's rapid pace of job nationalization, organizations should evaluate the current situation and possible changes happening in the labor market. It is clear that Omani people will make up a large portion of the workforce in the future. The findings of this study have emphasized the importance of recognizing and addressing the needs of the Omani workforce and suggesting organizations to formulate effective strategies to not only train potential citizen employees, but also to involve them effectively to utilize their talents and competencies in work for their own and the company's benefit.

According to Johnston (2015), an organization must attract and retain the best workers by developing an environment that promotes diversity. A healthy diversity climate includes top management commitment, an inclusion agenda, acceptance, work protection for all workers, and better working environment. Similarly, such organizational factors would be ineffective unless relational factors such as respect, justice, independence, and fairness, among others, are well practiced and executed in the organization. As stated by Moon, \& Christensen (2019) the human resource strategies that respect human assets and view them as a source of competitive advantage are critical and important. Managers should be aware of the advantages of achieving a positive diversity climate; otherwise, they would not prioritize the creation of a positive Diversity Climate. In today's globalized world, no business will thrive without a diverse workforce (McKay, P. F., Avery, D. R., Liao, H., \& Morris, M. A, 2011) Getting a diverse workforce isn't enough unless you build a healthy work environment for your workers. As a result, management practices and strategies should not only embrace diversity, but also ensure that it is handled appropriately. In today's fast-paced workplace, a successful company is one that embraces diversity as the norm rather than the exception (Catney, Gemma \& Lloyd, Christopher, 2020).

From the researcher's personal observation when speaking with employees of the organizations, it has been identified that "Wasta" (recognizing and promoting individuals based on a personal relationship or recommendation) is very common in Oman's organizations. When meeting and interviewing senior executives from a prominent oil and gas company who have lived in Oman for more than two decades and worked in a variety of companies in Oman and the GCC, it was discovered that it is standard practice around the organization to include, accept, and hire people based on personal relationships and recommendation "Wasta." They did say, however, that compassion, respect, and justice for all are valued highly in the organizations of Oman. This is one of the reasons why expatriates hold Oman's people and culture in such high regard and also because of their humble and kind nature. Following Covid19, most expatriate employees fear losing their employment due to the government's push for job nationalization, which has impacted and affected the psychological climate of expatriate employees. Some organizations are concerned about losing their expatriate workers, believing 
that they have made significant contributions to the organization's establishment and growth, while others are determined to keep them at all costs, and others claim that they are powerless in the face of new government orders to replace Omani in expatriate positions.

\subsection{Novelty of The Study and Scope for Future Research}

The study's uniqueness stemmed from the development of a new conceptual/theoretical framework for evaluating the diversity climate of Oman-based organizations. This study is helpful to understand the diversity climate and diversity practices of organizations in Oman especially after Covid. Previous research in the field of diversity climate did not concentrate on some of these aspects diversity climate and did not establish a clear relationship between them. Another significant contribution is the development of a model to explain the organizational and relational factors of diversity climate and their effect on employee conduct. This research suggests that a positive diversity climate is critical for an organization in which workers of various nationalities and backgrounds have an equal opportunity to engage in all of the company's activities. This study also found that the diversity climate in Omani organizations has changed and will continue to change in the coming days as a result of Covid 19 , which is influencing the mindset of employees, especially expatriate employees who are working in Oman's organizations. This research also benefits academia by providing a theoretical framework for understanding the diversity climate and its effect on employee behaviour, which can be used as a realistic managerial tool to promote a positive diversity climate.

This research on diversity climate has faced a range of challenges and limitations, and as a result, some guidelines and suggestions for future researchers have been made. The research suggests the potential researchers to study the diversity climate and its effect on employees' behaviour in the organizations of Oman after covid. This is an exploratory research that will make a valuable contribution to the diversity climate and diversity practices' literature. However, in order to make any generalizations, more research like this needs to be done in the future. This study focussed on employees' perceptions of diversity climate and it was done in Muscat city. Similar studies can be conducted in other parts of Oman for comparison purposes, as well as a comparative analysis after a few years of covid in the same or other parts of Oman. More research is required to examine the diversity climate from the perspective of employers, which will reveal the current state of diversity climate in Oman's organizations. Since psychological judgment and employees' perceptions of organizational and relational variables change over time, a larger sample size study must be used in future studies. Finally, the research model built in this study was based on existing literature on diversity. The replication of this study in other GCC countries, such as Bahrain, the United Arab Emirates, and Saudi Arabia, will help to improve our understanding of the diversity climate model and to learn how employees in other GCC countries view diversity climates.

\section{References}

Bassett-Jones, N. (2005); The paradox of diversity management, creativity and innovation: Creativity and Innovation Management, 14(2), 169-175.

Beechler, S., \& Woodward, I. C. (2009); The global "war for talent.": Journal of International Management, 15(3), 273-285. bejingLonelyPlanet (2019). https://www.lonelyplanet.com/ china/beijing

Bunderson, J. S., \& Sutcliffe, K. M. (2002); Comparing alternative conceptualizations of functional diversity in management teams: Process and performance effects. Academy of Management Journal, 45(5), 875-893. 
Catney, Gemma \& Lloyd, Christopher. (2020); Population Grids for Analysing Long-Term Change in Ethnic Diversity and Segregation: Spatial Demography. 8. 1-35. https://doi.org/10.1007/s40980-020-00071-6

Choi, S. (2008); Diversity in the US federal government: Diversity management and employee turnover in federal agencies: Journal of Public Administration Research and Theory, 19(3), 603-630.

Choi, S., \& Rainey, H. G. (2010); Managing diversity in US federal agencies: Effects of diversity and diversity management on employee perceptions of organizational performance: Public Administration Review, 70(1), 109-121.

Cooke, F. L., \& Saini, D. S. (2010); Diversity management in India: A study of organizations in different ownership forms and industrial sectors: Human Resource Management, $49(3), 477-500$.

De Cieri, H, Buttigieg, D, Pettit, T \& Costa, C 2008; Managing a diverse workforce: attraction and retention of older workers: Australian Centre for Research in Employment and Work, Caulfield East.

Groeneveld, S. (2011); Diversity and employee turnover in the Dutch public sector: Does diversity management make a difference? International Journal of Public Sector Management, 24(6), 594-612.

Groeneveld, S., \& Verbeek, S. (2012); Diversity policies in public and private sector organizations: An empirical comparison of incidence and effectiveness. Review of Public Personnel Administration, 32(4), 353-381.

Hofhuis, J., van der Rijt, P.G.A. \& Vlug, M. (2016); Diversity climate enhances work outcomes through trust and openness in workgroup communication.: SpringerPlus 5, 714 (2016). https://doi.org/10.1186/s40064-016-2499-4

Hostager, T. J., \& De Meuse, K. P. (2002); Assessing the complexity of diversity perceptions: Breadth, depth, and balance: Journal of Business and Psychology, 17(2), 189-206.

Hostager, T. J., \& De Meuse, K. P. (2008); The effects of a diversity learning experience on positive and negative diversity perceptions: Journal of Business and Psychology, 23(3-4), 127-139.

https://www.isixsigma.com/tools-templates/sampling-data/margin-error-and-confidencelevels-made-simple/.

https://www.omanobserver.om/expat-population-decline-by-9-3-in-2020/.

https://www.pewresearch.org/global/2016/10/18/middle-easts-migrant-population-more-thandoubles-since-2005/.

https://www.worldbank.org/en/country/gcc/publication/economic-update-october-2020-oman.

Jacob Poushter \& Janell Fetterolf, 2019; A Changing World: Global Views on diversity, gender, equality, family life and the importance of religion: https://www.pewresearch.org /global/2019/04/22/how-people-around-the-world-view-diversity-in-their-countries/.

Johnston, Ron \& Poulsen, Michael \& Forrest, James. (2015); Increasing Diversity Within Increasing Diversity: the Changing Ethnic Composition of London's Neighbourhoods, 2001-2011. Population, Space and Place. 21. 10.1002/psp.1838. 
Khan, Faisal \& Sohail, Amir \& Sufyan, Muhammad \& Uddin, Maaz \& Basit, Abdul. (2019); The effect of Workforce Diversity on Employee Performance in Higher Education Sector. Journal of Management Info. 6. 1-8. 10.31580/jmi.v6i3.515.

McKay, P. F., Avery, D. R., Liao, H., \& Morris, M. A. (2011); Does diversity climate lead to customer satisfaction? It depends on the service climate and business unit demography: Organization Science, 22(3), 788-803.

McKay, P. F., Avery, D. R., Tonidandel, S., Morris, M. A., Hernandez, M., \& Hebl, M. R. (2007); Racial differences in employee retention: Are diversity climate perception the key?: Personnel Psychology, 60(1), 35-62.

McKay, Patrick \& Avery, Derek. (2015); Diversity Climate in Organizations: Current Wisdom and Domains of Uncertainty: Research in Personnel and Human Resources Management. 33. 191-233. 10.1108/S0742-730120150000033008.

Moon, \& Christensen. (2019); Realizing the performance benefits of workforce diversity in the U.S. Federal Government: The moderating role of diversity climate. Public Personnel Management. Advance online publication. https://doi.org/10.1177/0091026019848458.

Mor Barak, M. E. (2015); Inclusion is the key to diversity management, but what is inclusion? Human Service Organizations: Management, Leadership \& Governance, 39(2), 83-88.

Newman, Alexander \& Nielsen, Ingrid \& Smyth, Russell \& Hirst, Giles. (2018); The effects of diversity climate on the work attitudes of refugee employees: The mediating role of psychological capital and moderating role of ethnic identity. Journal of Vocational Behavior. 105. 147-158. 10.1016/j.jvb.2017.09.005.

Nnadi, C. S. O., \& Chinedu, U. A. (2019); Effect of Diversity Management Strategies on Employee Retention among Staff of Nigeria Deposit Insurance Corporation. International Journal of Academic Research in Business and Social Sciences, 9(7), 999-1019.

Preeti bedi; Poonam lakra; Ekanshi Gupta, (2014); Workforce Diversity Management: Biggest Challenge or Opportunity For 21st Century Organizations: IOSR Journal of Business and Management (IOSR-JBM) e-ISSN: 2278-487X, p-ISSN: 2319-7668. Volume 16, Issue 4. Ver. III (Apr. 2014), PP 102-107, www.iosrjournals.org

Stazyk, E. C., Davis, R., \& Liang, J. (2012); Examining the Links between Workforce Diversity, Organizational Goal Clarity, and Job Satisfaction. In APSA 2012 Annual Meeting Paper.

Times of Oman, Oct. 2019: https://timesofoman.com/article/2040450/Oman/Oman-has-thesecond-most-diverse-workforce-in-the-Arab-world.

Weiliang, E. C. (2011); The Effects of Workforce Diversity towards the Employee Performance in an Organization (Doctoral Dissertation, Universiti Tunku Abdul Rahman). 